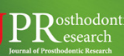 \\ Journal of Prosthodontic Research
}

\author{
Official Journal of Japan Prosthodontic Society
}

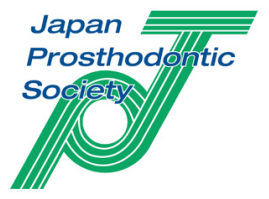

Original article

\section{Impact of hybrid layer formation on the 15-year survival, complications and failures of full-coverage retainers}

\author{
Morakot Piemjai*, Noppawan Adunphichet \\ Department of Prosthodontics, Faculty of Dentistry, Chulalongkorn University, Bangkok, Thailand
}

\begin{abstract}
Purpose: To compare the effect of 4-META/MMA-TBB resin, which can provide hybrid layer formation, and acid-base cements on survival, complications, and failure risks of full-coverage retainers evaluated for 15 years.

Methods: A total of 1,161 abutment teeth in 260 patients treated with at least one single crown or fixed partial denture were recalled for clinical examination. Survival was defined as not having undergone extraction of abutments or renewal of prostheses. Secondary caries, pulp necrosis, or prosthesis detachment were recorded as complications. Survival and complications rates were analyzed using the Kaplan-Meier method and log-rank test. Multivariable analysis of factors associated with failure or complications using Cox's proportional hazard regression model was performed $(\alpha=0.05)$.

Results: Significant differences were observed in survival $(p=0.007)$, secondary caries $(p=0.000)$, and prosthesis detachment $(p=0.025)$ complications between luting agents. The 5-, 10-, and 15-year survival rates for 4-META/MMA-TBB resin were $95.2 \%, 90.5 \%$, and $90.5 \%$, while those of acid-base cements were $93.2 \%, 80.6$, and $67.4 \%$, respectively. Secondary caries and prosthesis detachment complications for 4-META/MMA-TBB resin were $1.9 \%$ and $0.5 \%$, whereas those for acid-base cements were $15.2 \%$ and $4.3 \%$ respectively. Acid-base cements were associated with a 1.664-, 2.950-, 3.333-, and 4.444-times greater risk of failure, prosthesis renewal, secondary caries and prosthesis detachment, respectively.

Conclusions: 4-META/MMA-TBB resin has higher long-term survival rate with lesser caries and prosthesis detachment than acid-base cements. The ability of this resin to create an acid-base resistant hybrid layer may contribute to a life-long function of tooth abutment.
\end{abstract}

Keywords: Survival and complications, Hybrid layer, Secondary caries, Prosthesis detachment

Received 21 October 2020, Accepted 3 March 2021, Available online 29 July 2021

\section{Introduction}

Complications such as post-operative sensitivity, caries associated with restorations, as well as infection and/or necrosis of dental pulp are consequences of marginal microleakage [1,2]. The microleakage level at the cementum/dentin margin and at the interface for fixed prostheses using acid-base cements was found to be higher than that for a resin luting agent [3]. In laboratory investigations, hybridization of 4-methacryloyloxyethyl trimellitate anhydride in methyl methacrylate initiated by tri- $n$-butyl borane (4-META/MMA-TBB) into enamel and dentin to form a hybrid layer not only increases the bond strength, but also can resist acid demineralization, proteolytic degradation $[4,5]$, and microleakage $[3,6,7]$. This impermeable hybrid layer formed using $10 \%$ citric acid and $3 \%$ ferric chloride aqueous (10-3) conditioner and 4-META/MMA-TBB resin can be prepared in the oral cavity and can prevent oral microorganisms from reaching the dental pulp $[4,8]$. 4-META/MMA-TBB luting resin is a dry bonding system that requires separate etching, rinsing, and air-drying prior to fixation. Therefore, technical sensitivity to manipulation is high compared with conventional acid-base cements. However, it has been used as a drybonding luting agent with the same material composition, that is: 10-3

\footnotetext{
* Corresponding author at: Department of Prosthodontics, Faculty of Dentistry, Chulalongkorn University, 34 Henri-dunant Road, Pathumwan, Bangkok 10330, Thailand.

E-mail address: tmorakot@chula.ac.th (M. Piemjai).
}

conditioner, 4-META/MMA-TBB resin, and PMMA powder, for more than 30 years.

Clinical long-term studies suggest that biological complications such as dental caries, tooth fractures, pulp necrosis, and periodontal disease are major contributors to clinical failure in conventional crowns with acidbase cements $[9,10]$. The most common complication is secondary caries or caries initiated at the crown leakage. Acid-base cements, which set via an acid-base reaction such as zinc phosphate, zinc polycarboxylate, and glass ionomer, have been used for cementation of conventional crowns and in fixed partial dentures (FPDs) for many decades. Although easy to manipulate, these cements cannot form a hybrid layer, lack adhesive properties, are unable to form a complete seal, are soluble in the oral cavity, and have greater microleakage $[3,4,11,12]$. Though the estimated survival of single crowns or bridges retained either by glass ionomer or zinc phosphate cement was not significantly different $[13,14]$, none of the studies have compared the differences in short- or long-term clinical performance between 4-META/MMA-TBB resin and acid-base cements.

Mechanical failure, such as prosthesis detachment and/or fractures, can be repaired. However, the tooth structure cannot be regenerated. Thus, survival of a tooth abutment without biological failure is very critical for life-long function. The authors hypothesized that an adhesive resin luting agent, which can create an impermeable hybrid layer in prepared tooth abutments in the oral cavity, and have leakage-free margins at the toothprosthesis interfaces in laboratory investigations, should provide better clinical outcomes for fixed prostheses compared to when acid-base cements are used, which commonly leads to leakage.

The purpose of this retrospective clinical study was to compare the 
survival and complication rates of full-coverage crowns and FPDs fixed on tooth abutments with acid-base cements (zinc phosphate, zinc polycarboxylate or glass ionomer) or 4-META/MMA-TBB resin after 5 and 10 years as well as after 15 years of function. Other factors associated with failure and complications were also studied.

\section{Materials and Methods}

This study was approved by the Faculty Human Research Ethics Committee (Study Code HREC-DCU 2015-21). The inclusion criteria were patients who received at least a single full-coverage crown or FPD inserted by the institution's postgraduates under the supervision of specialist prosthodontics instructors between 1998 and 2009. The exclusion criteria were patients who were lost to follow-up or had missing treatment records; died or refused to participate; or were handicapped. A total of 260 patients volunteered for the study, and $83(31.9 \%)$ patients were male while 177 $(68.1 \%)$ were female. The minimum, maximum, and mean ages at the time of clinical examination were 31,88 and $61.44 \pm 10.81$ years, respectively. Volunteering patients were informed of the study's purpose before signing the consent forms.

\subsection{Data collection and clinical examination}

Patients' data on sex, age, and medical conditions were recorded before the clinical examination. There were 944 fixed prostheses, including 745 crowns and 199 FPDs, and 1,161 abutment teeth. All crown and FPD data, including type of cement used, type of prosthesis, prosthesis materials, distribution in the dental arch, endodontically treated abutments, service time since cementation, and any previous failure or complication were investigated.

Survival time was defined as the period from permanent cementation of prostheses until prosthesis removal or abutment extraction. Survival of prostheses meant that the prostheses were functional with or without repairable complications until the clinical evaluation date. Complications associated with the luting agents, such as secondary caries, pulp necrosis, and prosthesis detachment were calculated for both failure and survival groups. Failure and complication data before clinical evaluation in 2015 were collected from the patients' charts. Related data collected from the patients' charts were used for calculation when failure of abutment extraction or renewal of the prosthesis occurred. Complications of secondary caries that were not a cause of failure recorded in the patients' charts were not included to avoid any errors from un-calibrated operators.

The prosthesis and abutment examination was performed by one dentist, trained by professional instructors, using a mouth mirror and a no. 6 sharp probe. Caries associated with prostheses were determined following the Fédération Dentaire Internationale (FDI) guidelines [15]. Overhanging margins of the prostheses were corrected prior to caries investigation. The vitality of abutments was carefully examined using a pulp tester, tooth percussion, palpation of surrounding tissue, history-taking of pain, and periapical radiography. The periodontal health of abutments was determined as normal if the probing depth was less than $4 \mathrm{~mm}$, with no bleeding on probing.

\subsection{Statistical analysis}

A descriptive analysis and chi-square test were performed to analyze the frequency, minimum and maximum values, as well as the standard deviation of patients' general characteristics for each luting agent type and their differences, respectively. The survival and complication rates of abutment teeth were statistically analyzed using the Kaplan-Meier non-parametric method with SPSS for Windows version 17.0 (IBM Corporation, Somers, NY). A log-rank test was used to evaluate differences in survival and complication rates between the types of luting agents, prostheses, and prosthesis materials. Multivariable analysis was conducted using a Cox's proportional hazard regression model. The significance level was set at $\alpha=0.05$.

\section{Results}

\subsection{General characteristics of patients and abutment teeth}

The distribution of abutments related to the number of patients is presented in Figure 1. Majority of patients (78.8\%) had 1 to 5 abutments treated with crowns or FPDs. Of these 1,161 abutments, $64.2 \%$ were cemented with acid-base cements, while $35.8 \%$ were fixed with 4-META/ MMA-TBB resin (Superbond C\&B, Sun Medical, Shiga, Japan or C\&B Metabond, Parkell Inc., NY, USA), as shown in Table 1.

The distribution of abutment location and general characteristics related to the utilized luting agents are summarized in Figure 2 and Table 2, respectively. Crowns and FPDs were most frequently placed in patients aged 50-64 years. More abutments were fixed using a resin luting agent $(25.7 \%)$ than using acid-base cements $(16.0 \%)$ for patients older than 65 years old. More anterior abutments were fixed with 4-META/MMATBB resin $(38.2 \%)$ than with acid-base cements $(28.3 \%)$. Porcelain fused to metal (PFM) was the dominant material (73-74\%) used for prosthesis fabrication followed by full metal coverage (20-26\%) for both types of luting agents. All-ceramic prostheses (7.2\%) were luted using resin, while metal prostheses were predominantly cemented using acid-base cements $(26 \%)$ rather than resin $(19.5 \%)$. More crowns were retained by resin $(75.2 \%)$ than acid-base cements $(58.0 \%)$, whereas the number of FPDs cemented with acid-base cements $(42.0 \%)$ was nearly twice than those fixed with resin $(24.7 \%)$. No difference in number of vital $(55-56 \%)$ and root canal-treated (RCT) teeth (44-45\%) was found between luting agent groups. Most abutments were not involved in removable partial dentures (RPDs). Those involved were fixed with resin (29.3\%) more frequently than acid-base cements $(21.3 \%)$. Abutments luted with resin mostly had a follow-up period of 5-9.9 years $(86.7 \%)$, which was significantly higher than those cemented with acid-base cements $(53.3 \%)$.

\subsection{Failures of crowns and FPDs in relation to luting agent types}

Biological and prosthesis complications that caused abutment extraction or renewal of the prosthesis in relation to each luting agent type are presented in Table 3. Failures related to luting materials, such as secondary caries, pulp necrosis, and prosthesis detachment of the acid-base cements $(6.7 \%, 2.3 \%$, and $2.7 \%$ respectively) were more than those for 4-META/ MMA-TBB resin $(1.2 \%, 0.9 \%$, and $0 \%$ respectively). The most common failure found in crowns and FPDs cemented with acid-base cements was secondary caries, while tooth fracture was the most common reason for failure of 4-META/MMA-TBB resin.

\subsection{Comparison of survival, prosthesis renewal, and abutment extraction between luting agents}

The Kaplan-Meier and log-rank methods found significant differences (log-rank test $=7.355, p=0.007)$ in the estimated survival rates of crowns and FPDs cemented with different luting agents (Fig. 3). The survival rates $(\%)$ after 5,10 , and 15 years were $95.2 \pm 1.0,90.5 \pm 1.9$, and $90.5 \pm 1.9$ for resin and $93.2 \pm 0.9,80.6 \pm 1.7$, and $67.4 \pm 4.4$ for acid-base cements, respectively. The survival from prosthesis renewal after 5,10 , and 15 years for acid-base cements $(95.7 \pm 0.7,88.9 \pm 1.3$, and $82.5 \pm 2.5$ respectively) was significantly lower than that for 4-META/MMA-TBB resin (97.6 \pm 0.8 , $97.1 \pm 0.9$, and $97.1 \pm 0.9$ respectively) (log-rank test $=9.646, p=0.002$ ) (Fig. 4). No significant difference was observed in the survival from abutment extraction between luting agents (log-rank test $=0.419, p=0.517$ ) (Fig. 5). The survival rates (\%) from abutment extraction after 5,10 , and 15 years were $97.4 \pm 0.6,90.7 \pm 1.3$, and $81.8 \pm 4.7$ for acid-base cements and $97.6 \pm 0.8$, $93.2 \pm 1.8$, and $93.2 \pm 1.8$ for 4-META/MMA-TBB resin, respectively.

\subsection{Comparison of survival from caries, prosthesis detachment, and pulp necrosis complications between luting agents}

Secondary caries, prosthesis detachment, and pulp necrosis complications evaluated in this study causing failure or non-failure for acid-base cements were 15.2\% $(n=113), 4.3 \%(n=32), 7.1 \%(n=29)$, 


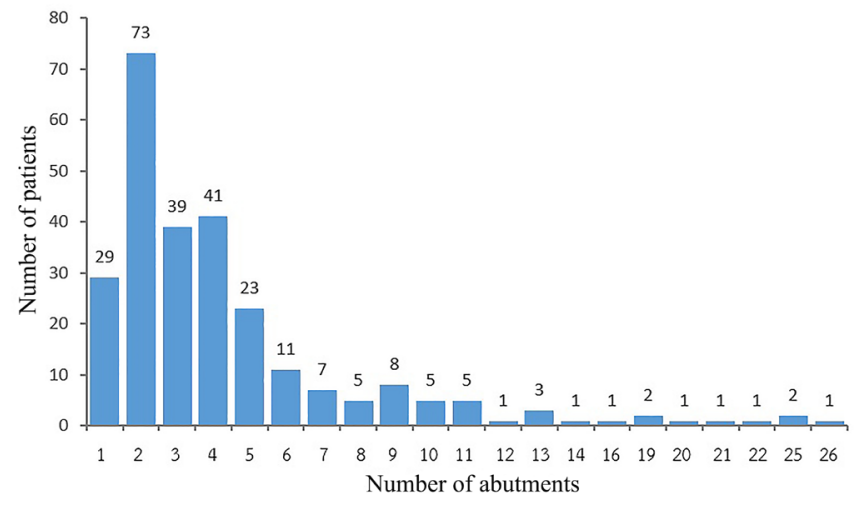

Fig. 1. Number of abutments related to number of patients.

Table 1. Frequency of used luting agent.

\begin{tabular}{lccc}
\hline & Type of luting agent & Number of abutment & $\%$ \\
\hline \multirow{2}{*}{ Acid-base } & Zinc phosphate & 486 & 41.9 \\
& Zinc polycarboxylate & 173 & 14.9 \\
& Glass ionomer & 86 & 7.4 \\
Resin & 4-META/MMA-TBB & 416 & 35.8 \\
\hline
\end{tabular}

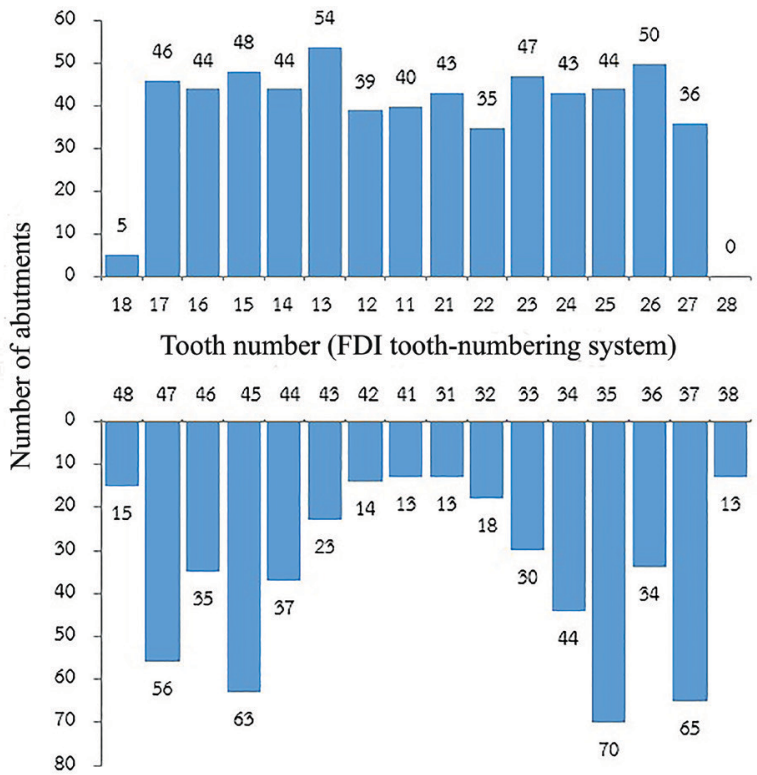

Fig. 2. Distribution of abutment teeth $(n=1,161)$.

Table 2. Distribution of abutments' characteristics related to luting agent type at time of cementation

\begin{tabular}{|c|c|c|c|c|c|c|}
\hline \multirow{2}{*}{\multicolumn{2}{|c|}{ Characteristics of abutments }} & \multicolumn{2}{|c|}{ Acid-base } & \multicolumn{2}{|c|}{ 4-META/MMA-TBB } & \multirow[b]{2}{*}{$p^{*}$} \\
\hline & & $\mathrm{n}=745$ & $\%$ & $\mathrm{n}=416$ & $\%$ & \\
\hline Gender & $\begin{array}{l}\text { - Male } \\
\text { - Female }\end{array}$ & $\begin{array}{l}288 \\
475\end{array}$ & $\begin{array}{l}38.7 \\
61.3\end{array}$ & $\begin{array}{l}144 \\
272\end{array}$ & $\begin{array}{l}34.6 \\
65.4\end{array}$ & 0.172 \\
\hline Patient age (year) & $\begin{array}{l}-20-34 \\
-35-49 \\
-50-64 \\
-\geq 65^{*}\end{array}$ & $\begin{array}{c}35 \\
223 \\
368 \\
119\end{array}$ & $\begin{array}{c}4.7 \\
29.9 \\
49.4 \\
16.0\end{array}$ & $\begin{array}{c}24 \\
103 \\
182 \\
107\end{array}$ & $\begin{array}{c}5.8 \\
24.8 \\
43.8 \\
25.7\end{array}$ & 0.000 \\
\hline Jaw & $\begin{array}{l}\text { - Maxilla } \\
\text { - Mandible }\end{array}$ & $\begin{array}{l}390 \\
355 \\
\end{array}$ & $\begin{array}{l}52.3 \\
47.7\end{array}$ & $\begin{array}{l}229 \\
187 \\
\end{array}$ & $\begin{array}{l}55.0 \\
45.0\end{array}$ & 0.377 \\
\hline Tooth position & $\begin{array}{l}\text { - Anterior* } \\
\text { - Premolar } \\
\text { - Molar }\end{array}$ & $\begin{array}{l}211 \\
261 \\
273\end{array}$ & $\begin{array}{l}28.3 \\
35.0 \\
36.6\end{array}$ & $\begin{array}{l}159 \\
135 \\
122 \\
\end{array}$ & $\begin{array}{l}38.2 \\
32.5 \\
29.3\end{array}$ & 0.002 \\
\hline Prosthesis materials & $\begin{array}{l}\text { - Full metal* } \\
\text { - Porcelain fused to metal } \\
\text { - All-ceramic* }\end{array}$ & $\begin{array}{c}194 \\
551 \\
0\end{array}$ & $\begin{array}{c}26.0 \\
74.0 \\
0\end{array}$ & $\begin{array}{c}81 \\
305 \\
30 \\
\end{array}$ & $\begin{array}{l}19.5 \\
73.3 \\
7.2 \\
\end{array}$ & 0.000 \\
\hline Type of prosthesis & $\begin{array}{l}\text { - Crown* } \\
\text { - FPD* }\end{array}$ & $\begin{array}{l}432 \\
313 \\
\end{array}$ & $\begin{array}{l}58.0 \\
42.0\end{array}$ & $\begin{array}{l}313 \\
103\end{array}$ & $\begin{array}{l}75.2 \\
24.7\end{array}$ & 0.000 \\
\hline Occluding pair & $\begin{array}{l}\text { - Natural teeth/crown } \\
\text { - Removable denture } \\
\text { - Implant }\end{array}$ & $\begin{array}{c}646 \\
97 \\
2 \\
\end{array}$ & $\begin{array}{c}86.7 \\
13.0 \\
0.3 \\
\end{array}$ & $\begin{array}{c}349 \\
66 \\
1 \\
\end{array}$ & $\begin{array}{c}83.9 \\
15.9 \\
0.2 \\
\end{array}$ & 0.408 \\
\hline Tooth vitality & $\begin{array}{l}\text { - Vital tooth } \\
\text { - Root canal treated teeth }\end{array}$ & $\begin{array}{l}408 \\
337 \\
\end{array}$ & $\begin{array}{l}54.8 \\
45.2 \\
\end{array}$ & $\begin{array}{l}234 \\
182 \\
\end{array}$ & $\begin{array}{l}56.3 \\
43.8 \\
\end{array}$ & 0.626 \\
\hline $\begin{array}{l}\text { Abutment of removable } \\
\text { denture* }\end{array}$ & $\begin{array}{l}\text { - No } \\
\text { - Yes }\end{array}$ & $\begin{array}{l}586 \\
159 \\
\end{array}$ & $\begin{array}{l}78.7 \\
21.3\end{array}$ & $\begin{array}{l}294 \\
112 \\
\end{array}$ & $\begin{array}{l}70.7 \\
29.3\end{array}$ & 0.002 \\
\hline Follow-up period (years) & $\begin{array}{l}-5-9.9^{*} \\
-10-14.9^{*} \\
-\geq 15\end{array}$ & $\begin{array}{c}397 \\
312 \\
36 \\
\end{array}$ & $\begin{array}{c}53.3 \\
41.9 \\
4.8 \\
\end{array}$ & $\begin{array}{c}361 \\
51 \\
4 \\
\end{array}$ & $\begin{array}{c}86.7 \\
12.2 \\
0.1 \\
\end{array}$ & 0.000 \\
\hline
\end{tabular}

*Significant difference using chi-square test at $p<0.05$

Table 3. Failures of crowns and FPDs for two types of luting agents $(n=1,611)$.

\begin{tabular}{llcccc}
\hline & & \multicolumn{2}{c}{ Acid-base } & 4-META/MMA-TBB \\
\cline { 3 - 6 } & \multicolumn{1}{c}{ Categories } & $\mathrm{n}=745$ & $(\%)$ & $\mathrm{n}=416$ & $(\%)$ \\
\hline Biological & Secondary caries & 50 & $(6.7)$ & 5 & $(1.2)$ \\
failure & Tooth fracture & 17 & $(2.3)$ & 12 & $(2.9)$ \\
& Pulp necrosis/vital tooth & $11 / 408$ & $(2.7)$ & $2 / 234$ & $(0.9)$ \\
& Periodontitis & 14 & $(1.9)$ & 6 & $(1.4)$ \\
Prosthesis & Prosthesis detachment & 19 & $(2.6)$ & 0 & $(0)$ \\
failure & Porcelain fracture & 10 & $(1.3)$ & 3 & $(0.7)$ \\
& Loose contact & 1 & $(0.1)$ & 1 & $(0.2)$ \\
\hline
\end{tabular}

and $1.9 \%(\mathrm{n}=8), 0.5 \%(\mathrm{n}=2), 4.3 \%(\mathrm{n}=10)$ for 4-META/MMA-TBB resin, respectively. Survival from complications of acid-base cements and 4-META/MMA-TBB resin significantly differed in secondary caries (logrank test $=12.711, p=0.000$ ) (Fig. 6) and prosthesis detachment (log-rank test $=4.998, p=0.025$ ) (Fig. 7). No significant difference was found in pulp necrosis (log-rank test $=0.329, p=0.566)$ between luting agent types (Fig. 8). Survival from complications related to luting agents after 5, 10, and 15 years are demonstrated in Table 4 . 


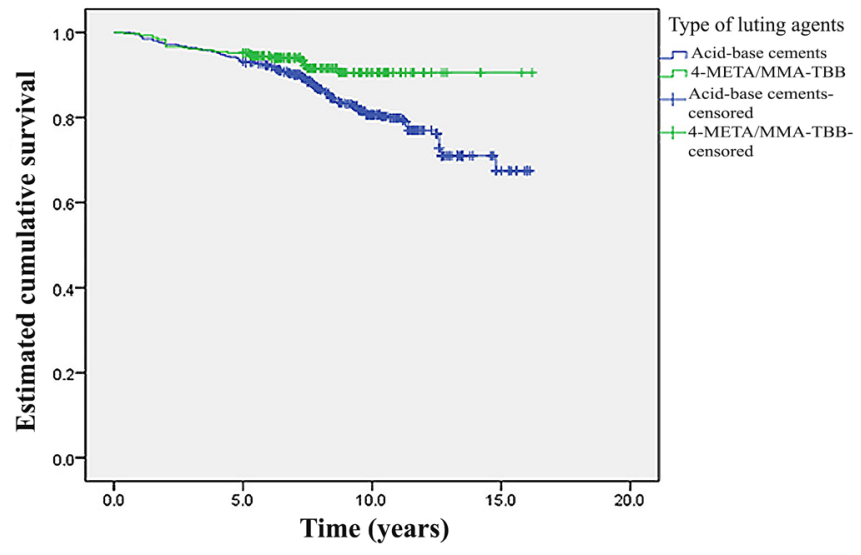

Fig. 3. Estimated cumulative survival rate of crowns and FPDs for different luting agent types with significant difference at $p=0.007$.

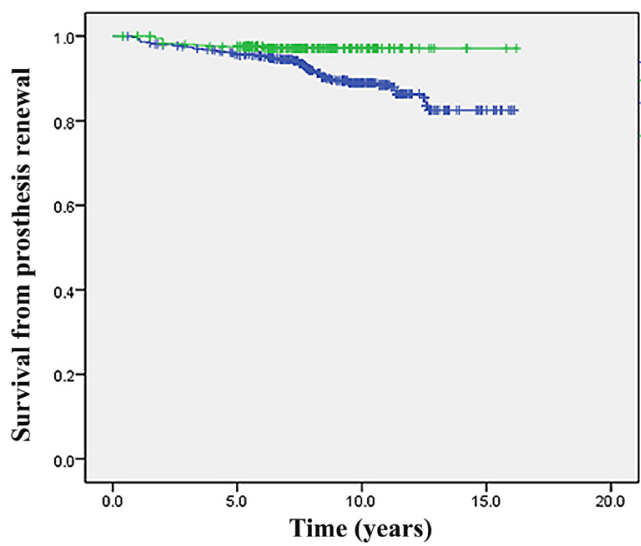

Fig. 4. Survival from prosthesis renewal for different luting agent types with significant difference at $p=0.002$.

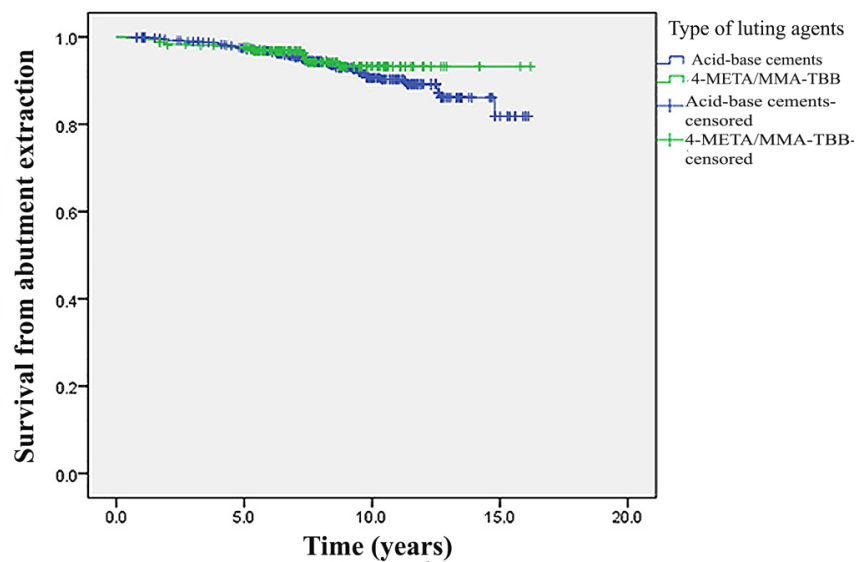

Fig. 5. Survival from abutment extraction for different luting agent types with no significant difference $(p=0.517)$.

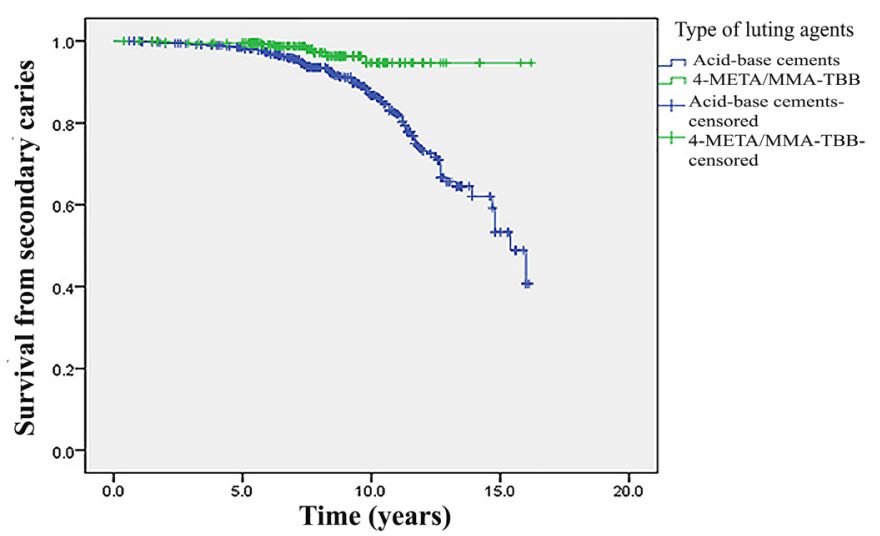

Fig. 6. Survival from secondary caries for different luting agent types with significant difference at $p=0.000$.

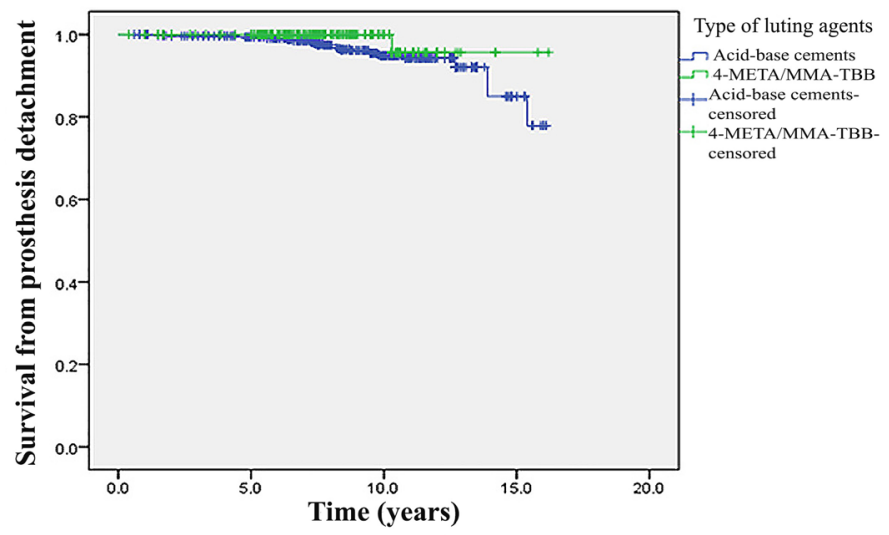

Fig. 7. Survival from prosthesis detachment for different luting agent types with significant difference at $p=0.025$.

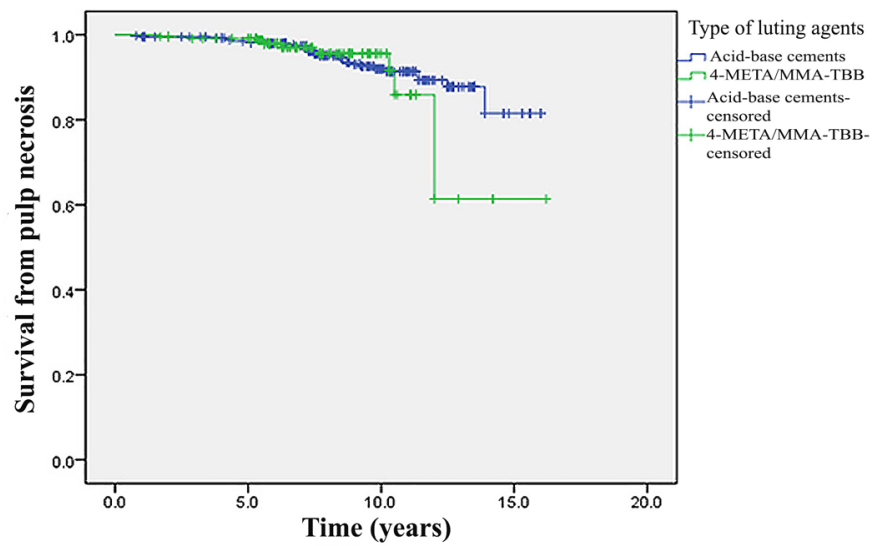

Fig. 8. Survival from pulp necrosis for different luting agent types with no significant difference $(p=0.566)$. 
Table 4. Distribution of survival (\%) from complications related to each luting agent type at 5,10 , and 15 years.

\begin{tabular}{lcccccc}
\hline & \multicolumn{5}{c}{ Acid-base } & \multicolumn{4}{c}{ 4-META/MMA-TBB } \\
\cline { 2 - 7 } Complications & 5 -year & 10 -year & 15 -year & 5-year & 10 -year & 15 -year \\
\hline $\begin{array}{l}\text { Secondary } \\
\text { caries* }\end{array}$ & $99.5 \pm 0.3$ & $86.8 \pm 1.6$ & $53.3 \pm 5.9$ & $99.5 \pm 0.3$ & $94.7 \pm 2.2$ & $94.7 \pm 2.2$ \\
$\begin{array}{l}\text { Prosthesis } \\
\text { detachment* }\end{array}$ & $99.3 \pm 0.3$ & $94.8 \pm 1.0$ & $85.0 \pm 5.1$ & $100.0 \pm 0.0$ & $95.7 \pm 3.0$ & $95.7 \pm 3.0$ \\
$\begin{array}{l}\text { Pulp necrosis } \\
\text { * Significant difference between luting agent types at } p<0.05\end{array}$
\end{tabular}

* Significant difference between luting agent types at $p<0.05$

3.5. Comparison of estimated survival, survival from caries, prosthesis detachment, and pulp necrosis complications among acid-base cements

The Kaplan-Meier and log-rank methods found no significant differences (log-rank test $=0.020, p=0.990)$ in the estimated survival rates of crowns and FPDs fixed with different acid-base cements (Fig. 9A). The survival rates $(\%)$ were $95.5 \pm 0.9,79.8 \pm 2.2$, and $64.4 \pm 5.0$ after 5,10 , and 15 years for zinc phosphate, respectively, and $88.4 \pm 2.4,83.0 \pm 3.0$ and 89.5 \pm 3.3 , $76.9 \pm 5.0$ after 5 and 10 years for zinc polycarboxylate and glass ionomer cements, respectively. No significant differences were found in terms of survival from complications of secondary caries (log-rank test $=2.117, p=$ 0.347) (Fig. 9B), prosthesis detachment (log-rank test $=2.054, p=0.358)$ (Fig. 9C), and pulp necrosis (log-rank test $=0.518, p=0.772$ ) (Fig. 9D) among the acid-base cements. Secondary caries, prosthesis detachment, and pulp necrosis complications using acid-base cements either causing failure or non-failure were $15.2 \%(\mathrm{n}=74), 4.7 \%(\mathrm{n}=23)$, and $6.0 \%(\mathrm{n}=$ 13) for zinc phosphate; $16.2 \%(n=28), 2.3 \%(n=4)$, and $7.7 \%(n=11)$ for zinc polycarboxylate; and $12.8 \%(\mathrm{n}=11), 5.8 \%(\mathrm{n}=5)$, and $9.8 \%(\mathrm{n}=5)$ for glass ionomer, respectively.

\subsection{Comparison of estimated survival and survival from complications} between types of prosthesis

The estimated survival rate between types of prosthesis, crowns and FPDs, was significantly different (log-rank test $=8.776, p=0.003)$ (Fig. $10 \mathrm{~A})$. The cumulative survival rates $(\%)$ after 5,10 , and 15 years were $95.2 \pm 0.8,86.4 \pm 1.6$, and $72.1 \pm 6.2$ for crowns and $91.6 \pm 1.4,77.6 \pm 2.4$, and $68.3 \pm 4.1$ for FPDs, respectively. No significant difference was found in survival from caries (log-rank test $=1.456, p=0.227$ ) (Fig. 10B), prosthesis detachment (log-rank test $=0.945, p=0.331)$ (Fig. 10C), and pulp necrosis (log-rank test $=0.415, p=0.520)$ (Fig. 10D) complications between crowns and FPDs.

\subsection{Comparison of estimated survival and survival from complications among prosthesis materials}

The Kaplan-Meier and log-rank methods found no significant differences (log-rank test $=0.818, p=0.664)$ in the estimated survival rates of crowns and FPDs fabricated using different prosthesis materials: metal, PFM, and all-ceramic (Fig. 11A). The survival rates (\%) after 5, 10 , and 15 years were $94.2 \pm 1.4,83.4 \pm 2.8$, and $76.8 \pm 4.6$ for full metal; 93.9 $\pm 0.8,82.5 \pm 1.6$, and $66.8 \pm 6.1$ for PFM; and $90.0 \pm 5.5$ after 5 years for all-ceramic, respectively. No significant difference was found among prosthesis materials in terms of survival from the following complications: secondary caries (log-rank test $=0.914, p=0.663)$ (Fig. 11B), prosthesis detachment (log-rank test $=0.373, p=0.830)($ Fig. 11C), and pulp necrosis $(\log$-rank test $=1.859, p=0.395)($ Fig. 11D $)$.

3.8. Multivariable analysis using the Cox's proportional hazard regression model

Factors that influenced the failure rates of abutments and/or prostheses using Cox's proportional hazard regression and multivariable analysis are illustrated in Table 5. Male patients had a 1.931-times greater risk of abutment extraction than female patients. Premolar abutments had a greater risk of prosthesis renewal (1.815-times) than anterior abutments. Fixed partial dentures had failure rates and rates of prosthesis renewal 1.813and 2.747-times greater, respectively, when compared to crowns. Allceramic materials had an 11.024-times higher risk for prosthesis renewal than full metal ones. Acid-base cements contributed to failure rates and prosthesis renewal 1.664- and 2.950-times more than 4-META/MMA-TBB resin. RCT teeth had 1.511- and 2.213-times greater risks of failures and abutment extraction than vital teeth, respectively. Abutments of RPDs had a 2.232-times higher risk for abutment extraction than non-abutment teeth.

Factors influencing secondary caries, prosthesis detachment, and pulp necrosis were analyzed using Cox's proportional hazard regression and multivariable analysis, which are shown in Table 6. Female patients had a 2.521-times greater risk of pulp necrosis than male patients. Patients older than 50 years, FPD abutments, removable denture occluding, and acid-base cements had influences on the secondary caries, with these factors putting them 1.883-, 1.701-, 1.875-, and 3.333-times more at risk, respectively. Acid-base cements had a 4.444-times greater risk of prosthesis detachment than 4-META/MMA-TBB resin.

\section{Discussion}

The clinical data for this study were collected from patients treated by postgraduate students in the prosthodontics department of the faculty of dentistry; therefore, the treatment consensus, operators, operation procedures, laboratory quality, materials used, and working environment were controlled. Patients were treated using either 4-META/MMA-TBB resin or acid-base cements depending on the instructors' expertise. These factors contributed to more standardized clinical data compared with those derived from dentists in general private clinics or meta-analysis data from multi-centers.

The cumulative survival rate and survival from prosthesis renewal of retainers fixed with the resin luting agent were significantly higher than for acid-base cements (Fig 3,4). The most common failure found in the acid-base group was secondary caries $(6.7 \%)$, which was similar to previous reports $[9,16-18]$. This was followed by pulp necrosis $(2.7 \%)$ and prosthesis detachment $(2.6 \%)$, as shown in Table 3 . There was no prosthesis detachment, but minor failures from secondary caries $(1.2 \%)$ and pulp necrosis $(0.9 \%)$ were found in the resin group. Failures not related to the luting agents, such as abutment fractures, periodontal disease, porcelain fractures, and loose prosthesis contacts were not different between luting agent types (Table 3 ). The survival from secondary caries and prosthesis detachment for 4-META/MMA-TBB were significantly higher than for those acid-base cements (Table 4, Fig 6, 7). Crowns and FPDs fixed with acid-base cements had a greater risk of failure, prosthesis renewal, secondary caries, and prosthesis detachment, with each being 1.664-, 2.95-, 3.333-, and 4.444-times, respectively, compared with the resin luting agent (Table 5,6). These clinical findings suggest that 4-META/MMA-TBB resin, which can prevent leakage in laboratory experiments $[3,6,7]$ and form a hybrid layer both in vitro and in vivo $[4,5,8]$, increases the survival rate of crowns and FPDs with less complications of secondary caries and prosthesis detachment compared with those cemented with acid-base cements having marginal leakage $[3,19]$, and thus improves both short and long-term function. Our study results support this hypothesis.

Acids in acid-base cements can penetrate the dentin and demineralize hydroxyl apatite crystals during cementation [20]. Demineralized dentin has micro-porosities, which are leakage pathways for dye and silver nitrate tracers $[3,6,7,21,22]$. Dentin hybridization using 4-META/MMA-TBB resin creates a complete hybrid layer over intact dentin, which resists acid demineralization and sodium hypochlorite degradation and provides leakage-free margins at the tooth-restoration interface [4-8]. Lactic acid, one of the major contributors in causing caries, can penetrate leakage pathways faster than on the root surface and demineralize the dentin further to form secondary caries-like lesions or wall-lesions [22]. An impermeable hybrid layer with a microleakage-free cementum/dentin margin and interface can resist lactic acid demineralization better than the adjacent root surface [22]. These might be the reason why crowns and FPDs cemented with this luting agent had a high survival rate with less secondary caries.

This clinical observation also suggests that full-coverage retainers fixed 
A

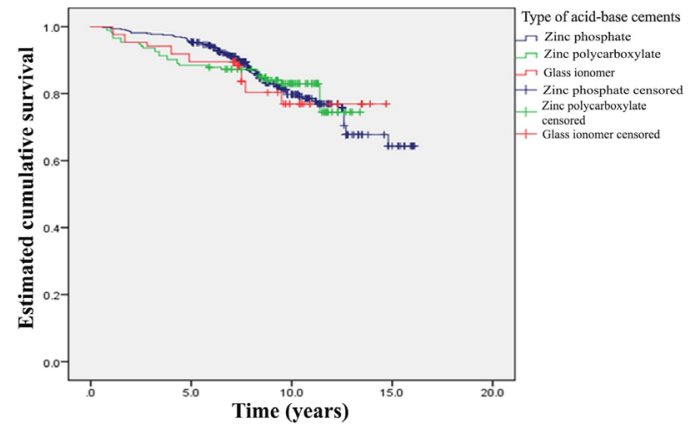

$\mathrm{C}$

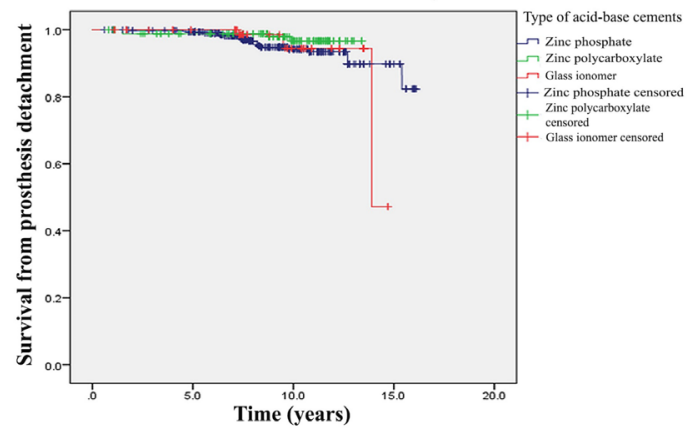

B

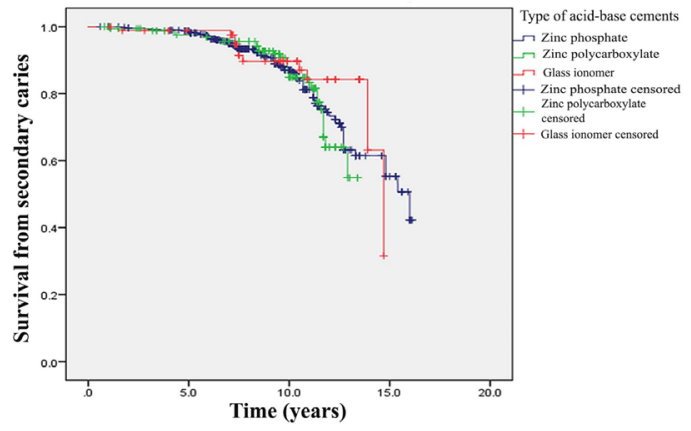

$\mathrm{D}$

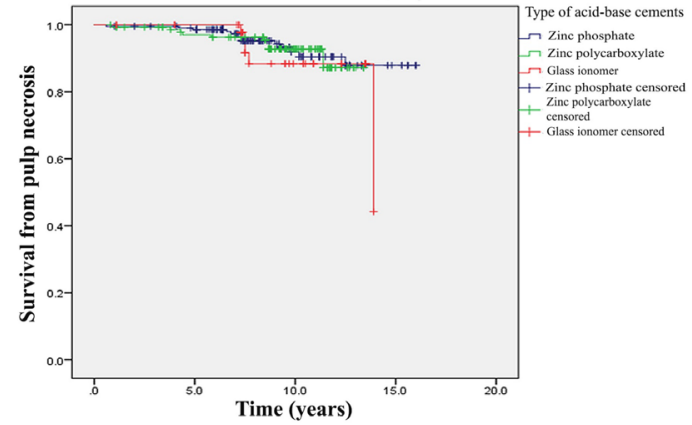

Fig. 9. Crowns and fixed partial dentures cemented with different acid-base cements demonstrating no significant difference in: estimated cumulative survival ( $p=0.990)$ (A), survival from secondary caries $(p=0.347)(B)$, survival from prosthesis detachment $(p=0.358)(C)$, and survival from pulp necrosis $(p=0.772)$ (D).

A

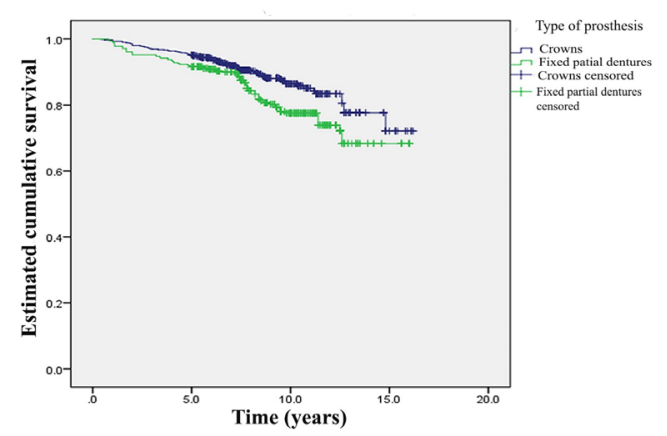

$\mathrm{C}$

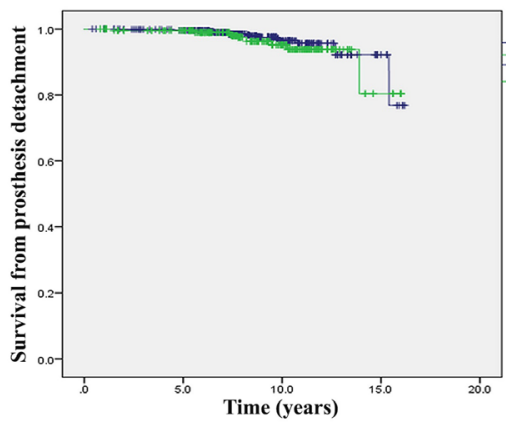

B

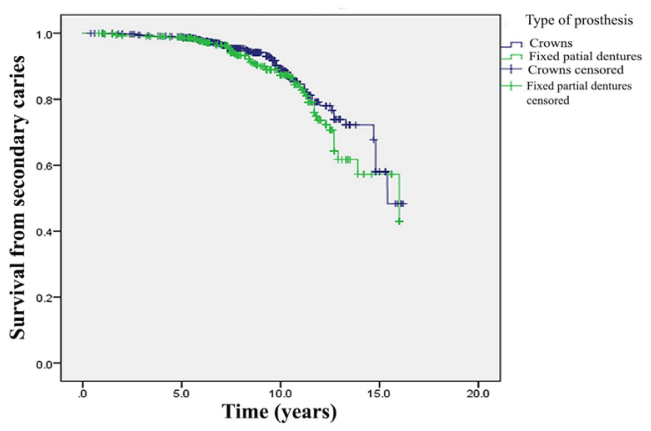

$\mathrm{D}$

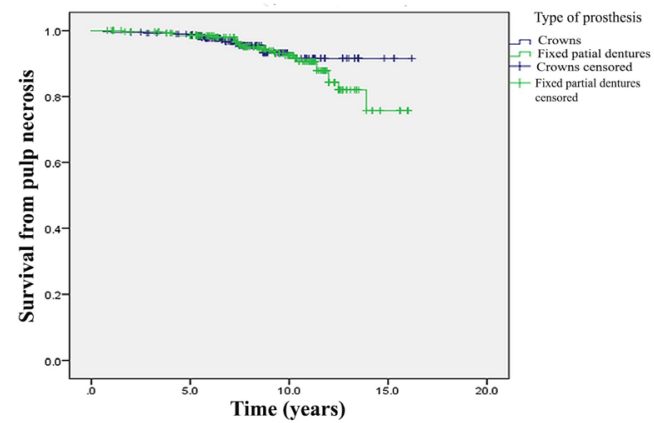

Fig. 10. Comparison between types of prosthesis demonstrating a significant difference in estimated cumulative survival $(p=0.003)(\mathrm{A})$, no significant difference in: survival from secondary caries $(p=0.227)$ (B), survival from prosthesis detachment $(p=0.331)(\mathrm{C})$, and survival from pulp necrosis $(p=0.520)$ (D). 
A

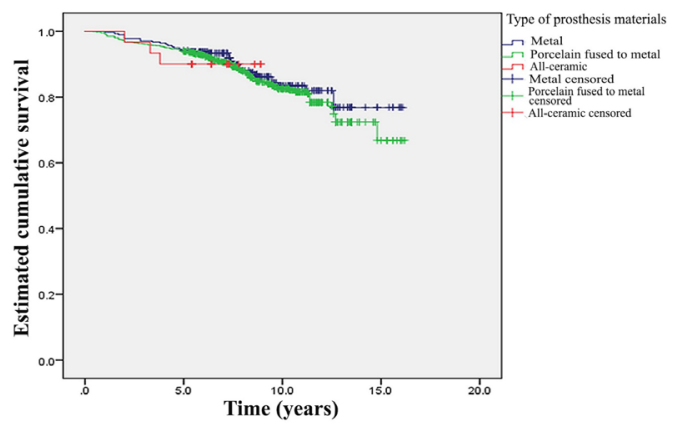

$\mathrm{C}$

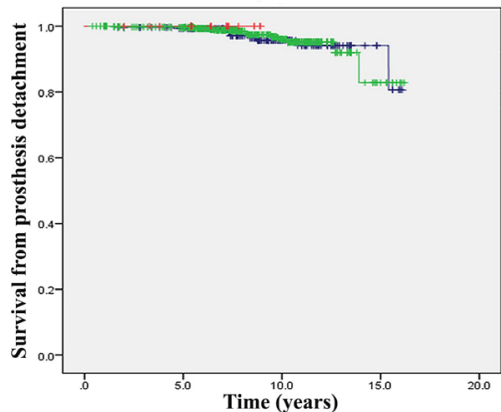

$\mathrm{B}$

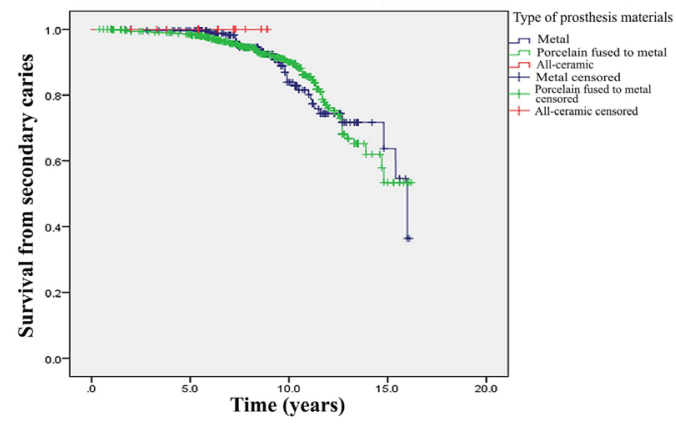

$\mathrm{D}$

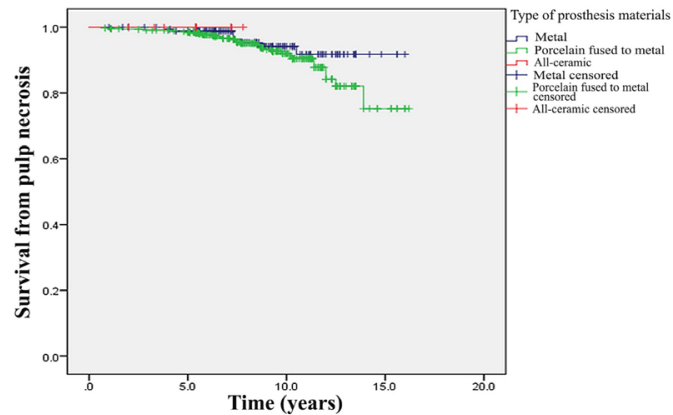

Fig. 11. Comparison among types of prosthesis materials demonstrating no significant difference in: estimated cumulative survival $(p=0.664)$ (A), survival from secondary caries $(p=0.663)(\mathrm{B})$, survival from prosthesis detachment $(p=0.830)(\mathrm{C})$, and survival from pulp necrosis $(p=0.395)(\mathrm{D})$.

Table 5. Cox-regression analysis on failure rates, prosthesis renewal, and abutment extraction.

\begin{tabular}{|c|c|c|c|c|c|c|c|}
\hline \multirow{2}{*}{ Factors } & \multirow{2}{*}{ Variables } & \multicolumn{6}{|c|}{ Hazard ratio $(95 \% \mathrm{CI})$} \\
\hline & & Total failures & $p$ & Prosthesis renewal & $p$ & Abutment extraction & $p$ \\
\hline Gender & Male/Female & & & $\begin{array}{c}1 / 1.220 \\
(0.750-1.985) \\
\end{array}$ & 0.423 & $\begin{array}{c}1 / 0.518 \\
(0.326-0.823) \\
\end{array}$ & $0.005^{*}$ \\
\hline Age (years) & $20-49 / \geq 50$ & $\begin{array}{c}1 / 1.274 \\
(0.910-1.785)\end{array}$ & 0.159 & & & $\begin{array}{c}1 / 1.406 \\
(0.824-2.401)\end{array}$ & 0.212 \\
\hline \multirow[t]{2}{*}{ Tooth position } & Anterior/Premolar & $\begin{array}{c}1 / 1.391 \\
(0.938-2.063) \\
\end{array}$ & \multirow{2}{*}{$\begin{array}{l}0.101 \\
0.555\end{array}$} & $\begin{array}{c}1 / 1.815 \\
(1.006-3.275) \\
\end{array}$ & \multirow{2}{*}{$\begin{array}{c}0.048 * \\
0.075\end{array}$} & & \\
\hline & Anterior/Molar & $\begin{array}{c}1 / 1.130 \\
(0.753-1.696) \\
\end{array}$ & & $\begin{array}{c}1 / 1.942 \\
(0.936-4.030)\end{array}$ & & & \\
\hline Type of prosthesis & Crown/FPD & $\begin{array}{c}1 / 1.813 \\
(1.313-2.503) \\
\end{array}$ & $0.000^{*}$ & $\begin{array}{c}1 / 2.747 \\
(1.678-4.497) \\
\end{array}$ & $0.000 *$ & $\begin{array}{c}1 / 1.314 \\
(0.752-2.296) \\
\end{array}$ & 0.338 \\
\hline \multirow[t]{2}{*}{ Prosthesis materials } & Full metal/PFM & & & $\begin{array}{c}1 / 1.329 \\
(0.684-2.581) \\
\end{array}$ & \multirow{2}{*}{$\begin{array}{c}0.402 \\
0.002 *\end{array}$} & $\begin{array}{c}1 / 1.481 \\
(0.826-2.652) \\
\end{array}$ & \multirow{2}{*}{$\begin{array}{l}0.187 \\
0.968\end{array}$} \\
\hline & Full metal/All-ceramic & & & $\begin{array}{c}1 / 11.024 \\
(2.457-49.464) \\
\end{array}$ & & $\begin{array}{c}1 / 0.000 \\
(0.000-3.757) \\
\end{array}$ & \\
\hline \multirow[t]{2}{*}{ Occluding pair } & $\begin{array}{l}\text { Natural tooth } \\
\text { /Removable denture }\end{array}$ & $\begin{array}{c}1 / 1.297 \\
(0.853-1.971) \\
\end{array}$ & \multirow{2}{*}{$\begin{array}{l}0.223 \\
0.209\end{array}$} & $\begin{array}{c}1 / 1.442 \\
(0.789-2.635)\end{array}$ & \multirow{2}{*}{$\begin{array}{l}0.235 \\
0.070\end{array}$} & $\begin{array}{c}1 / 1.179 \\
(0.659-2.108) \\
\end{array}$ & \multirow{2}{*}{$\begin{array}{l}0.579 \\
0.988\end{array}$} \\
\hline & $\begin{array}{l}\text { Natural tooth } \\
\text { /Implant }\end{array}$ & $\begin{array}{c}1 / 3.577 \\
(0.489-26.148) \\
\end{array}$ & & $\begin{array}{c}1 / 6.539 \\
(0.857-49.888) \\
\end{array}$ & & $\begin{array}{c}1 / 0.000 \\
(0.000-.)\end{array}$ & \\
\hline Luting agent type & $\begin{array}{l}\text { 4-META/MMA-TBB/ } \\
\text { Acid-base }\end{array}$ & $\begin{array}{c}1 / 1.664 \\
(1.104-2.513) \\
\end{array}$ & $0.015^{*}$ & $\begin{array}{c}1 / 2.950 \\
(1.410-6.173) \\
\end{array}$ & $0.004 *$ & & \\
\hline Vitality & Vital/RCT & $\begin{array}{c}1 / 1.511 \\
(1.097-2.081) \\
\end{array}$ & $0.012 *$ & & & $\begin{array}{c}1 / 2.213 \\
(1.371-3.571) \\
\end{array}$ & $0.001^{*}$ \\
\hline Denture abutment & $\mathrm{No} / \mathrm{Yes}$ & & & $\begin{array}{c}1 / 0.489 \\
(0.213-1.125) \\
\end{array}$ & 0.092 & $\begin{array}{c}1 / 2.232 \\
(1.332-3.739)\end{array}$ & $0.002 *$ \\
\hline
\end{tabular}

* Significant difference at $p<0.05$

with 4-META/MMA-TBB resin can provide retention against functional loading better than those fixed with acid-base cements (Fig. 7, Table $4,6)$. The tensile bond strength of 4-META/MMA-TBB resin to 10-3 conditioned enamel and dentin was optimum, approximately $15 \mathrm{MPa}$ and $20 \mathrm{MPa}$, respectively [4]. When this resin was used as the luting agent between the tooth and metal alloy or ceramic, the detachment mostly occurred at the prosthesis-resin interface with an average tensile strength of 9-12 MPa $[23,24]$. Failure modes at the resin-prosthesis interface during tensile testing of dentin restored with cast metal or ceramic using minidumbbell shaped specimens suggested that molecular-entangled retention 
Table 6. Cox-regression analysis on secondary caries, prosthesis detachment, and pulp necrosis.

\begin{tabular}{|c|c|c|c|c|c|c|c|}
\hline \multirow{2}{*}{ Factors } & \multirow{2}{*}{ Variables } & \multicolumn{6}{|c|}{ Hazard ratio $(95 \% \mathrm{CI})$} \\
\hline & & Secondary caries & $p$ & Prosthesis detachment & $p$ & Pulp necrosis & $p$ \\
\hline Gender & Male/Female & & & & & $\begin{array}{c}1 / 2.521 \\
(1.158-5.490) \\
\end{array}$ & $0.020^{*}$ \\
\hline Age (year) & $20-49 / \geq 50$ & $\begin{array}{c}1 / 1.883 \\
(1.220-2.906)\end{array}$ & $0.004 *$ & & & & \\
\hline \multirow[t]{2}{*}{ Tooth position } & Anterior/Premolar & $\begin{array}{c}1 / 0.687 \\
(0.421-1.119)\end{array}$ & 0.132 & & & & \\
\hline & Anterior/Molar & $\begin{array}{c}1 / 1.059 \\
(0.688-1.630) \\
\end{array}$ & 0.794 & & & & \\
\hline Type of prosthesis & Crown/FPD & $\begin{array}{c}1 / 1.701 \\
(1.104-2.621)\end{array}$ & $0.016^{*}$ & $\begin{array}{c}1 / 1.373 \\
(0.670-2.817)\end{array}$ & 0.387 & & \\
\hline Prosthesis materials & Full metal/PFM & & & & & $\begin{array}{c}1 / 1.628 \\
(0.748-3.545)\end{array}$ & 0.219 \\
\hline Occluding pair & $\begin{array}{l}\text { Natural tooth } \\
\text { /Removable denture }\end{array}$ & $\begin{array}{c}1 / 1.875 \\
(1.212-2.902) \\
\end{array}$ & $0.005^{*}$ & $\begin{array}{c}1 / 1.351 \\
(0.507-3.598) \\
\end{array}$ & 0.547 & & \\
\hline Luting agent type & $\begin{array}{l}\text { 4-META/MMA-TBB/ } \\
\text { Aid-base }\end{array}$ & $\begin{array}{c}1 / 3.333 \\
(1.610-6.897) \\
\end{array}$ & $0.001 *$ & $\begin{array}{c}1 / 4.444 \\
(1.056-18.868) \\
\end{array}$ & $0.042 *$ & & \\
\hline Vitality & Vital/RCT & $\begin{array}{c}1 / 1.464 \\
(0.997-2.149) \\
\end{array}$ & 0.052 & & & & \\
\hline Denture abutment & $\mathrm{No} / \mathrm{Yes}$ & $\begin{array}{c}1 / 1.303 \\
(0.793-2.143) \\
\end{array}$ & 0.296 & $\begin{array}{c}1 / 0.568 \\
(0.184-1.753) \\
\end{array}$ & 0.325 & & \\
\hline
\end{tabular}

*Significant difference at $p<0.05$

gained from a hybrid layer was much higher than that from resin tags, airblasting, and air-blasting plus porcelain primer [24,25] even if noble alloy primer (V-PRIMER) or silane-based coupling agent (Porcelain Liner M) pre-treatment on sandblasted prosthesis surfaces was recommended by the manufacturer to enhance resin adhesion. Thus, the tooth surface abutment is protected by an impermeable hybrid layer from oral stimuli even after prosthesis detachment $[4,25]$. This might be the reason that there was no failure from prosthesis detachment that caused abutment extraction or renewal of crowns and FPDs luted using 4-META/MMA-TBB resin in this study (Table 3). Many short molar abutments, mostly of the third molars, were selected to use this resin luting agent rather than using acidbase cements, which required crown lengthening and/or intentional pulp removal. All cases were free of prosthesis detachment during the long-term follow-up ( 7 abutments, no detachment, no caries). This implies that the critical advantage of a complete seal with high retention observed with the use of 4-META/MMA-TBB resin may maintain the vitality of the tooth for life-long function.

No statistically significant difference in pulp necrosis complication was found between acid-base $(2.7 \%)$ and resin $(0.9 \%)$ luting agents (Fig 8., Table 3). The 4-META/MMA-TBB resin uses a dry bonding technique with a 10-3 aqueous conditioner for $10 \mathrm{~s}$ on the dentin surface. Longer conditioning periods of $30-60 \mathrm{~s}$ can cause incomplete impregnation of resin, which leave demineralized dentin underneath to become a microleakage pathway [7, 22]. Prepared abutments with sub-gingival finish lines are susceptible to gingival fluid accumulation during cementation. Therefore, gingival retraction using a cord is recommended to maintain the dryness of air-dried demineralized substrate. Phosphoric acid is also recommended by the manufacturer as an enamel conditioner. However, when the prepared abutment surface is composed of both dentin and enamel, the 10-3 conditioner must be used for tooth conditioning to retain the permeability of air-dried demineralized dentin for complete monomer impregnation with no primer pre-treatment [4,24-26]. Phosphoric acidetched dentin collapses after air-drying and causes severe leakage toward the pulp chamber [7]. Thus, technical caution and knowledge is very important for complete resin hybridization to form a hybrid layer with a leakage-free margin and interface. As this resin cures automatically in the presence of water and oxygen, it can be used for all prosthesis materials, such as metal, PFM, and all-ceramic, for long-term function as shown in this study.

The cumulative survival rate, survival from secondary caries, prosthesis detachment, and pulp necrosis of retainers cemented with different acidbase cements were not significantly different (Fig. 9). Zinc phosphate, zinc polycarboxylate, and glass ionomer cements set via an acid-base reaction and lack a hybrid layer formation. Phosphoric acid or polyacrylic acid from acidic slurries can etch through smear layers and demineralize the underlying dentin substrate before cements setting $[4,20]$. Demineralized dentin with exposed collagen, smear layers, and the set cements can slowly dissolve and erode over time in the oral fluids $[4,11,12]$. The estimated survival rates of crowns and FPDs cemented with these acid-base cements after 5 and 10 years were $86-96 \%$ and $71-82 \%$, respectively, which are higher than those of previous reports after 5 years $(80-85 \%)$, but similar after 10 years $(70-80 \%)$ [14]. The most common failure and complication are the same, namely secondary caries [9,10,14-18].

There were significant differences in the estimated survival (Fig. 10A) and no significant difference in survival from complications (Fig. 10B, 10C, 10D) between the types of prosthesis, namely crowns and FPDs. While no significant difference was found in the estimated survival and survival from complications among prosthesis materials, namely metal, PFM, and allceramic (Fig. 11). Multivariable analysis of factors associated with failures or complications using Cox's regression revealed that abutments of FPDs had a 2.747- and 1.701-times greater risk of failure from prosthesis renewal and secondary caries than crown abutments (Table 5,6), while premolar abutments had a 1.815-times greater risk of prosthesis renewal than anterior teeth (Table 5). These results vary across reports $[9,27,28]$. The current study suggests that it might be related to the greater effect of the luting agent used (Table 5 , Hazard Ratio: $H R=2.950$ ) because the number of FPD abutments cemented with acid-base cements $(42.0 \%)$ were higher than those fixed with 4-META/MMA-TBB resin $(24.7 \%)$ while the number of anterior abutments luted with this resin (38.2\%) were higher than those cemented with acid-base cements (28.3\%) (Table 2). All-ceramic crowns had an 11.024-times greater risk of renewal than metal crowns (Table 5). The cause of failure was ceramic fractures, which was similar to those in previous reports $[29,30]$. These long-term clinical findings suggest that the 4-META/MMA-TBB luting resin has a high impact on protecting tooth abutments, regardless of the prosthesis type or material used.

Male patients had a greater risk of abutment extraction (1.931-times) than female patients (Table 5), while pulp necrosis complication was 2.521-times greater as a risk factor in females (Table 6). This suggests that more female patients opted to retain their teeth with root canal treatment rather than extraction, which was more common in male patients. RCT teeth and abutments of RPDs were the major contributors for abutment extraction in this study with an HR of 2.213- and 2.232-times, respectively (Table 5), while others reported 4.0- [27] and 5.5- [31] times, respectively. There were 1.883- and 1.875-times greater risks of developing secondary caries in patients with ages $\geq 50$ years and having removable denture occluding pairs, respectively (Table 6). These findings 
require further investigations related to the patient's ability to remove dental plaque [32].

\section{Conclusion}

This retrospective study results suggest that the 4-META/MMA-TBB resin provides significantly higher survival rates up to 15 years for fullcoverage retainers compared with acid-base cements. The most common failures and complications with acid-base cements were secondary caries and prosthesis detachment, which were significantly greater than that with 4-META/MMA-TBB resin. Complete hybridization of resin into enamel and dentin to form a hybrid layer with higher bond strength and a complete seal is suggested to be the major mechanism that could explain these clinical outcomes. Selection of the luting material highly influences longterm clinical function of tooth abutments for crowns and FPDs.

\section{Disclosure}

The authors have no conflict of interest.

\section{Acknowledgements}

The authors would like to express their appreciation to Senior Associate Professor John Harcourt, The University of Melbourne, for the editorial suggestions.

\section{References}

[1] Bergenholtz G, Cox CF, Loesche WJ, Syed SA. Bacterial leakage around dental restorations: its effect on the dental pulp. J Oral Pathol 1982;11:439-50.

[2] Brännström M. The cause of postrestorative sensitivity and its prevention. J Endod 1986;12:475-81.

[3] Piemjai M, Miyasaka K, Iwasaki Y, Nakabayashi N. Comparison of microleakage of three acid-base luting cements versus one resin-bonded cement for Class V direct composite inlays. J Prosthet Dent 2002;88:598-603.

[4] Nakabayashi N, Pashley DH. (1998) Hybridization of dental hard tissue. Tokyo: Quintessence, 1998

[5] Nakabayashi N. Bonding of restorative materials to dentine: the present status in Japan. Int Dent J 1985;35:145-54.

[6] Piemjai M, Thaveeratana A, Nakabayashi N. Marginal integrity between a prefabricated composite block and enamel, DEJ, and dentin. Am J Dent 2010;23:285-91.

[7] Piemjai M, Watanabe A, Iwasaki Y, Nakabayashi N. Effect of remaining demineralised dentine on dental microleakage accessed by a dye penetration: how to inhibit microleakage? J Dent 2004;32:495-501.

[8] Nakabayashi N, Ashizawa M, Nakamura M. Identification of a resin-dentin hybrid layer in vital human dentin created in vivo: durable bonding to vital dentin. Quintessence Int 1992;23:135-41.

[9] De Backer H, Van Maele G, De Moor N, Van den Berghe L, De Boever J. An 18-year retrospective survival study of full crowns with or without posts. Int J Prosthodont 2006; 19:136-42

[10] Walton TR. The up to 25-year survival and clinical performance of 2,340 high gold-based metal-ceramic single crowns. Int J Prosthodont 2013;26:151-60
[11] Sakaguchi RL, Power JM. The oral environment. In: Power JM, editor. Craig's restorative dental material. 13 ed. Elsevier, 2011.

[12] Phillips RW, Swartz ML, Lund MS, Moore BK, Vickery J. In vivo disintegration of luting cements. J Am Dent Assoc 1987;114:489-92.

[13] Black SM, Charlton G. Survival of crowns and bridges related to luting cements. Restorative Dent 1990;6:26-30.

[14] Jokstad A, Mjör IA. Ten years' clinical evaluation of three luting cements. J Dent 1996;24:309-15.

[15] Hickel R, Peschke A, Tyas M, Mjör I, Bayne S, Peters M, et al. \FDI World Dental Federation: clinical criteria for the evaluation of direct and indirect restorations-update and clinical examples. Clin Oral Investig 2010;14:349-66.

[16] Creugers NH, Käyser AF, van 't Hof MA. A meta-analysis of durability data on conventional fixed bridges. Community Dent Oral Epidemiol 1994;22:448-52.

[17] Pjetursson BE, Bragger U, Lang NP, Zwahlen M. Comparison of survival and complication rates of tooth-supported fixed dental prostheses (FDPs) and implant-supported FDPs and single crowns (SCs). Clin Oral Implants Res 2007:18 Suppl 3:97-113.

[18] Bart I, Dobler B, Schmidlin K, Zwahlen M, Salvi GE, Lang NP, et al. Complication and failure rates of tooth-supported fixed dental prostheses after 7 to 19 years in function. Int J Prosthodont 2012;25:360-7.

[19] Tjan AH, Dunn JR, Grant BE. Marginal leakage of cast gold crowns luted with an adhesive resin cement. J Prosthet Dent 1992;67:11-5.

[20] Shimada Y, Kondo Y, Inokoshi S, Tagami J, Antonucci JM. Demineralizing effect of dental cements on human dentin. Quintessence Int 1999;30:267-73.

[21] Piemjai M, Waleepitackdej O, Garcia-Godoy F, Nakabayashi N. Dentin protection by a primer-less adhesive technique. Am J Dent 2011;24:284-8.

[22] Piemjai M, Chantarawej P, Nakabayashi N, Garcia-Godoy F. Prognosis test by visualization of demineralized dentin under restorations to prevent initial walllesions initiated by lactic acid. Am J Dent 2017;30:119-24.

[23] Sen D, Nayir E, Pamuk S, Comparison of the tensile bond strength of highnoble, noble, and base metal alloys bonded to enamel. J Prosthet Dent 2000;84:561-6.

[24] Piemjai M, Nakabayashi N, Direct Tensile Strength and Characteristics of Dentin Restored with All-Ceramic, Resin-Composite, and Cast Metal Prostheses Cemented with Resin Adhesives. Biomed Res Int 2015. doi.10.1155/2015/656948.

[25] Piemjai M. Dentin protection for life-long function. Bangkok: Samcharoen Panich, 2015.

[26] Piemjai M, Iwasaki Y, Nakabayashi N. Influence of dentinal polyelectrolytes on wet demineralized dentin, a bonding substrate. J Biomed Mater Res A 2001;66:789-94.

[27] Palmqvist S, Soderfeldt B. Multivariate analyses of factors influencing the longevity of fixed partial dentures, retainers, and abutments. J Prosthet Dent 1994:71:245-50.

[28] Burke FJ, Lucarotti PS. Ten-year outcome of crowns placed within the General Dental Services in England and Wales. J Dent 2009;37:12-24.

[29] Dhima M, Paulusova V, Carr AB, Rieck KL, Lohse C, Salinas TJ. Practicebased clinical evaluation of ceramic single crowns after at least five years. J Prosthet Dent 2014;111:124-30.

[30] Beier US, Kapferer I, Dumfahrt H. Clinical long-term evaluation and failure characteristics of 1,335 all-ceramic restorations. Int J Prosthodont 2012;25:70-

[31] Miyamoto T, Morgano SM, Kumagai T, Jones JA, Nunn ME. Treatment history of teeth in relation to the longevity of the teeth and their restorations: outcomes of teeth treated and maintained for 15 years. J Prosthet Dent 2007;97:150-6.

[32] De Backer H, Van Maele G, De Moor N, Van den Berghe L. Survival of complete crowns and periodontal health: 18-year retrospective study. Int J Prosthodont 2007;20:151-8.

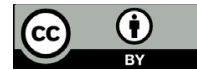

Copyright: This is an open-access article distributed under the terms of Creative Commons Attribution License 4.0 (CCBY 4.0), which allows users to distribute and copy the material in any format so long as attribution is given to the author(s). 